\title{
Effect of Different Starches on the Choice of Diet by Rats
}

\author{
BY D. E. TRIBE* AND J. G. GORDON \\ Rowett Research Institute, Bucksburn, Aberdeenshire
}

(Received $25 \mathcal{F u l y ~ 1 9 5 2 )}$

In the experiment reported here an attempt has been made to determine whether rats offered a free choice between two compound diets, identical except in their starch content and both deficient in the vitamin B complex, would select the one on which they could synthesize the required vitamins by refection. In the process of refection, first investigated by Fridericia (1926), rats are able to utilize the products of an endogenous bacterial synthesis of the vitamin B complex, occurring mainly in the caecum. Refection takes place in rats only when certain carbohydrates are present in the diet. Kon (193I) has shown that raw potato starch as a rule allows refection, whereas steamed potato starch and raw rice starch do not, and Baker, Nasr \& Morrice (1949) found that raw maize starch does not.

\section{EXPERIMENTAL}

Diets. The composition of the diets used in this experiment is shown in Table r. All diets, with the exception of 37 , contained no added B-vitamins and could not

Table I. Composition of the four experimental diets

\begin{tabular}{|c|c|c|c|}
\hline \multirow[b]{2}{*}{ Constituent } & \multicolumn{3}{|c|}{ Diet no. } \\
\hline & 12 & 16 & 36 \\
\hline Casein (vitamin-free) $(\mathrm{g})$ & $23^{\circ}$ & 230 & 230 \\
\hline Glucose (g) & 330 & 330 & 330 \\
\hline Margarine (g) & I 50 & 150 & I 50 \\
\hline McCollum salts I $85(\mathrm{~g})$ & 50 & 50 & 50 \\
\hline Potato starch, unground $(\mathrm{g})$ & 400 & -- & - \\
\hline Maize starch, unground (g) & - & 400 & - \\
\hline Rice starch, unground $(\mathrm{g})$ & - & - & 400 \\
\hline \multirow[t]{2}{*}{ Radiostoleum (vitamins A and D) (ml.) } & 4 & 4 & 4 \\
\hline & \multicolumn{3}{|c|}{$\begin{array}{l}\text { Diet } 37 \text {, the same } \\
\text { as diet } x 6 \text { with the } \\
\text { following vitamin } \\
\text { supplement } \\
(\mathrm{mg} / \mathrm{1} 00 \mathrm{~g})\end{array}$} \\
\hline Thiamine & \multicolumn{3}{|c|}{0.3} \\
\hline Pyridoxin hydrochloride & \multicolumn{3}{|c|}{$0 \cdot 3$} \\
\hline Riboflavin & \multicolumn{3}{|c|}{0.3} \\
\hline Calcium pantothenate & \multicolumn{3}{|c|}{$2 \cdot 0$} \\
\hline Nicotinic acid & \multicolumn{3}{|c|}{$4 \cdot 0$} \\
\hline$i$-Inositol & \multicolumn{3}{|c|}{10.0} \\
\hline p-Aminobenzoic acid & \multicolumn{3}{|c|}{$10 \cdot 0$} \\
\hline
\end{tabular}

* Present address: Bristol University Veterinary Laboratory, Langford House, Langford, near Bristol. 
therefore sustain normal growth in the absence of refection. Diets 12 and 16 were the same as those used by Baker et al. (1949) and diets $3^{6}$ and 37 were slight modifications of them. The vitamin supplement in diet 37 was almost the same as that used by Agnew \& Cook (1948-9) in their experiments on pyridoxin deficiency. It will be observed that diet $\mathbf{I} 2$ is the only one allowing refection to take place. A preliminary trial had confirmed some unpublished results of Richards (I948) on the palatability of the diets. It was found that diet 12 was distinctly less palatable than either 16 or $3^{6}$, which were of approximately equal palatability.

Management of rats. The experiment involved the use of three litters each of eight hooded 'Lister' rats. The rats were divided into four groups, each of six animals, in such a way that the groups were comparable in sex and litter of origin. Before being offered the experimental diets the rats were reared on the Rowett Institute stock diet. When each weighed approximately $100 \mathrm{~g}$ each rat was placed in a separate cage, measuring $10 \times 10 \times 5$ in. and with a fine-mesh portable mat as floor.

Arrangement of experiment. The diets were distributed among the groups in the following way:

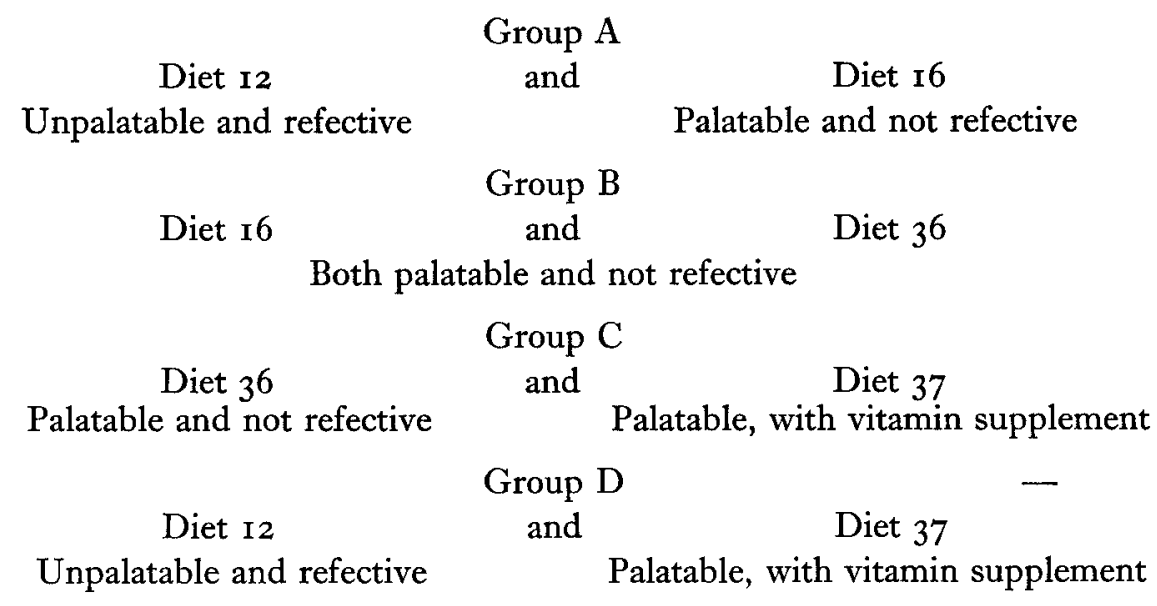

Each animal was offered $\mathrm{I}_{5} \mathrm{~g}$ of each diet, and the difference between this and the daily residue was taken as the amount consumed. All the feeding pots were identical in shape and colour, the positions in the cages were altered at irregular but frequent intervals. Beneath the meshed floor of each cage was placed a sheet of paper to collect any food scattered by the rat, but this seldom amounted to an appreciable quantity. All the animals were weighed daily, and they received tap water without stint.

\section{RESULTS AND DISCUSSION}

On the assumption that appetite is determined by physiological need, the behaviour of each group could be expected to follow a predictable pattern. The rats of group A would presumably begin by eating the more palatable diet, i.e. I6, but, after the effects of avitaminosis had been experienced, the preference values would be reversed and diet $\mathrm{I} 2$ would be eaten in greater quantities in order to remedy the deficiency. However, if such a pattern of behaviour did result, it might be said that a rat given 
a choice between any two diets would eat one for a time and then, for the sake of variety, change over and eat the other. It was therefore necessary to have three other groups so as to determine whether a rat's choice of food will vary from one diet to another irrespective of their nutritional significance. Since the diets offered to group $B$ were of equal palatability and both not refective, they would presumably be eaten in approximately similar quantities, sometimes more of one and sometimes more of the other, in the rats' attempts to find something to remedy the inevitable deficiency. In groups $\mathrm{C}$ and $\mathrm{D}$, where the animals had access to diet 37 , which was both palatable and nutritionally adequate, it was to be expected that they would eat this rather than diets 36 or 12 . This is certainly the behaviour that would be expected if appetite were conditioned by nutritional need, but the results include some interesting diversions from this expected pattern.

The average daily food intakes and body-weight changes for each animal in each group are given in Table 2.

Group $A$. An examination of the results for group A shows that diet 16 was eaten in larger quantities than diet I 2 throughout the experiment, the body-weights declined steadily and all the animals died. In this experiment appetite could not have been conditioned by nutritional need, but another point must be considered.

Kon (193 I) included an account of one individual that died after eating potato starch for 5 days. At autopsy the intestines were found to be enormously distended with gas, and the mesenteric vessels were pathologically distended with blood. $\mathrm{He}$ offered no suggestions as to the cause of this condition. Baker (1948), for no obvious reason, lost a rat fed on diet I2; post-mortem examination revealed an enlarged and inflamed stomach and small intestine. One animal in the preliminary palatability trial of this experiment died after eating diet $\mathrm{I} 2$ for $\mathrm{I} 2$ days. Post-mortem examination showed that the wall of the small bowel was congested, distended and thinned. There were multiple subperitoneal haemorrhages on the anterior aspect of the caecum. The caecum contained pultaceous yellow material, and the small bowel was nearly empty. It must be stated, however, that this was the only rat dying out of a group of twelve fed exclusively on diet 12 .

This finding, together with the purely qualitative observation that rats fed on potato starch look more miserable than those fed on maize starch, suggests that those eating potato starch experience abdominal or digestive discomforts not experienced by those eating maize starch. The evidence cited above, however, suggests that the rats in group $\mathrm{A}$ had the choice between a diet that allowed refection but caused abdominal discomfort and a diet that was not refective but did not cause discomfort.

Group B. As expected, the rats in group B showed no marked preference for either diet 16 or diet 36 , some choosing slightly more of diet 16 and others slightly more of diet 36 , but they all died.

Group C. It is interesting to see that, although the rats of group B did not discriminate between the rice-starch diet and the maize-starch diet, those of group $\mathrm{C}$ all showed a very marked preference for the maize-starch diet with the added vitamin supplement. It thus appears certain that these animals were responding to the vitamin content of diet 37 , and it seems reasonable to assume that, as previously 
Vol. 7

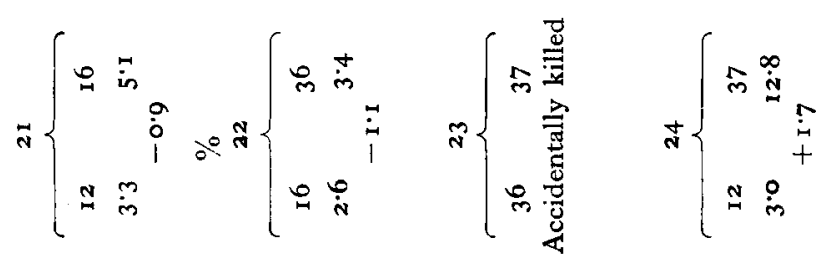

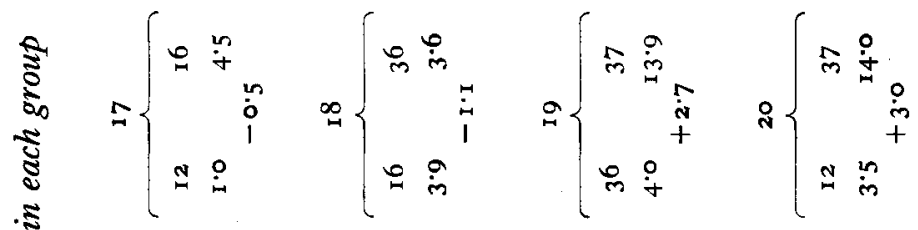

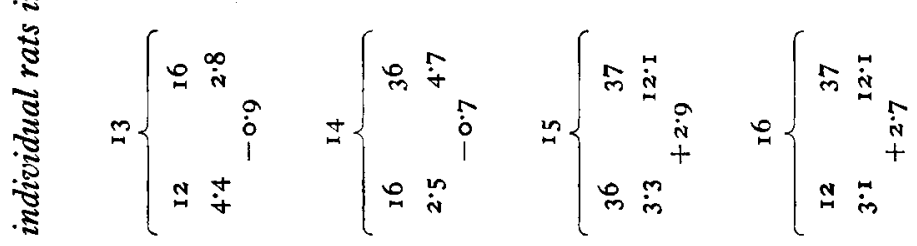

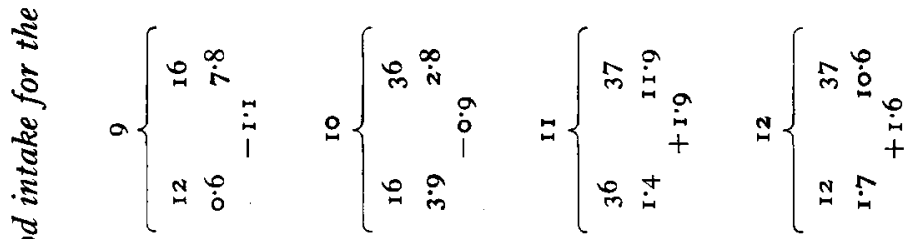

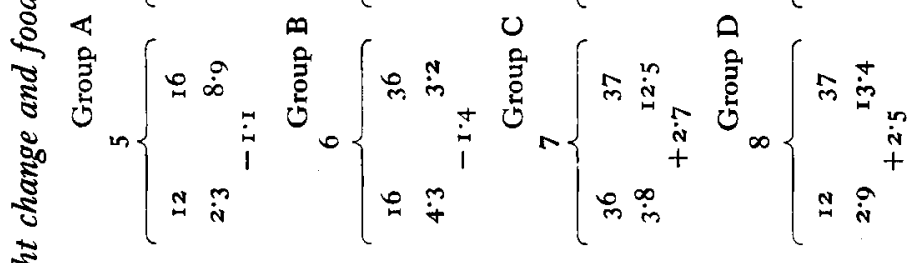

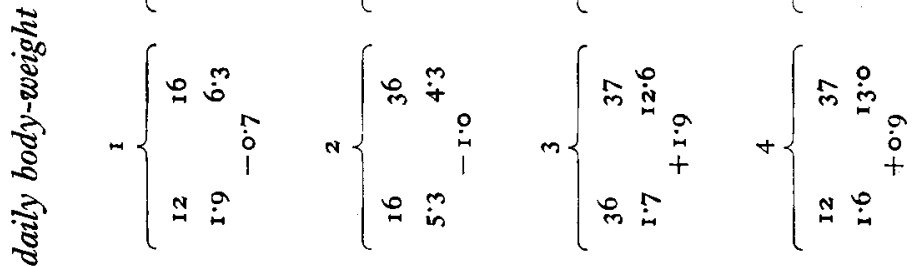

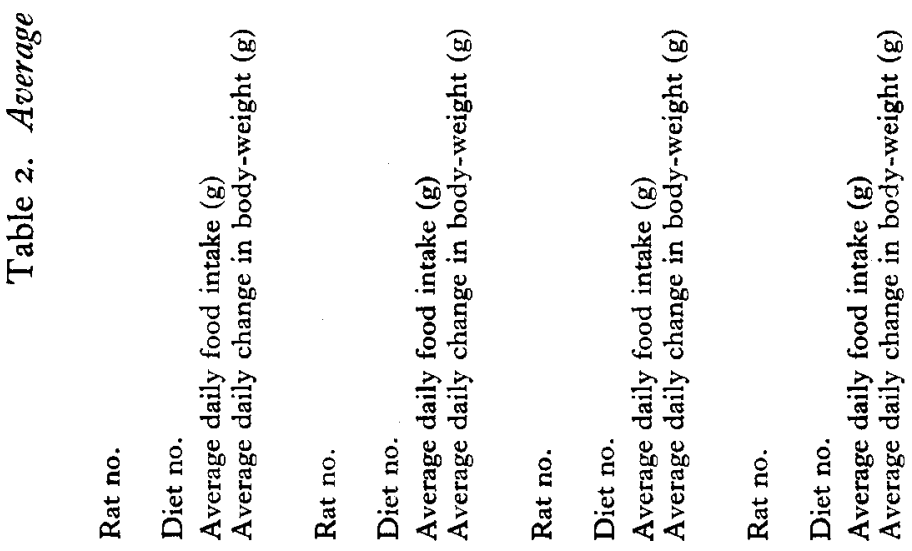


suggested by Harris, Clay, Hargreaves \& Ward (1933), the rats were able to relate a feeling of well-being to the consumption of a particular diet.

Group D. These rats behaved similarly to those in group $\mathrm{C}$ and chose the diet containing the vitamin supplement in preference to that without. However, the results with group A show that the rats would have chosen diet 37 with or without the vitamin supplement, and thus their behaviour may not be associated with the vitamin content of the diet chosen.

The possible influence of tactile sensation on the behaviour of group $A$. The mechanism involved in the discriminating behaviour of group A must ultimately be associated with one, or more than one, of the special sense organs. In the present experiment it seemed unlikely that a rat could distinguish between the taste, smell

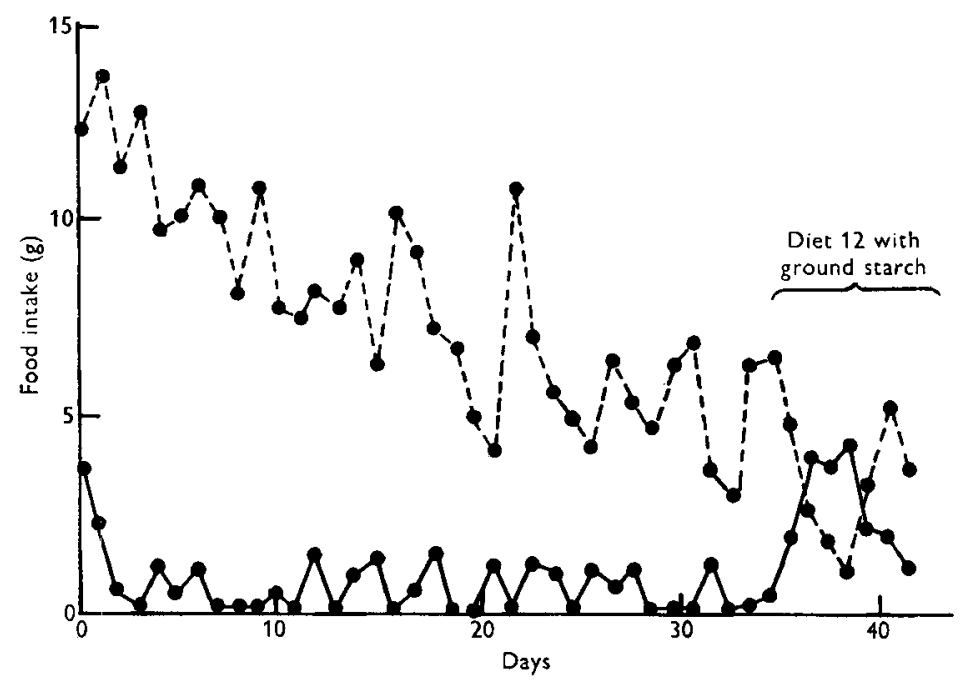

Fig. I. The food intake record of rat no. 9. ----, diet 16 ; —, diet 12.

or sight of maize and potato starch. The following evidence, however, though involving only two animals, suggests that rats can distinguish between the texture of the two starches.

Rat no. 9 in group A was given the choice between diets 12 and $\mathrm{I} 6$ and, following the pattern already described, showed a definite preference for 16 . After $3^{6}$ days the unground potato starch in diet $\mathbf{1} 2$ was replaced by potato starch that had been ground in a ball mill to $98 \%$ solubility in cold water. When the rat was faced with the alternatives of diet 16 and the amended diet 12 , its preference changed and the consumption of diet 12 increased. The food intake records are illustrated graphically in Fig. I.

A pattern of behaviour unlike that of the other rats in group A was shown by rat no. I3. It will be seen from Table 2 that this was the only animal consuming more of diet 12 than of diet 16 , although it did not eat enough of diet 12 to maintain it in good health. After 33 days' administration of diets 12 and 16 the unground potato starch in diet 12 was replaced by ground, as with rat no. 9. At once the preference values were reversed and none of the amended diet 12 was eaten. After 9 days the unground 
potato starch was reintroduced to diet 12 , and immediately the preference values returned to their previous levels (Fig. 2).

Microscopic examination of the three starches showed that the particles of the unground potato starch were the largest, those of the ground potato starch the smallest. It is possible that such differences may become evident to the animal through its tactile sense.

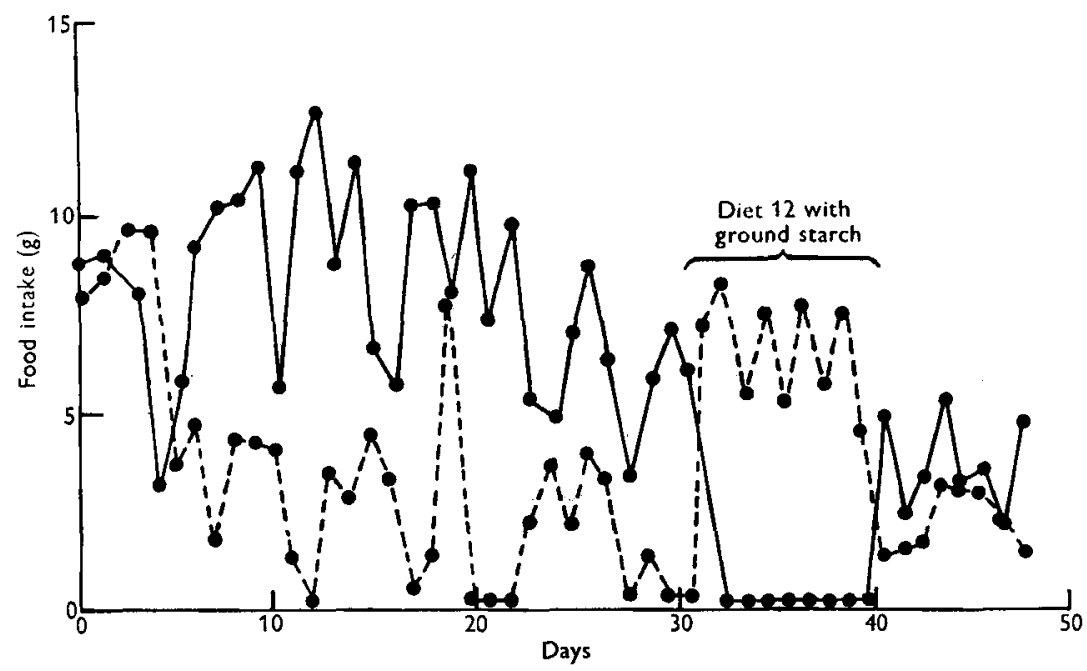

Fig. 2. The food intake record of rat no. I3. --_, diet 16; - , diet 12.

\section{SUMMARY}

I. Twenty-four hooded 'Lister' rats divided into four equal groups, were each given a choice between two diets.

2. Of those animals allowed to choose between a palatable diet, deficient in the vitamin $B$ complex, and an unpalatable diet, producing refection, all died, presumably because they did not select a sufficient amount of the diet permitting refection.

3. Those animals allowed to choose between two palatable diets, both deficient in the vitamin B complex, chose equal quantities of both.

4. Those rats allowed to choose between a palatable diet, deficient in vitamin $B$ complex, an unpalatable diet producing refection and a palatable and completely adequate diet, all chose the palatable and adequate diet.

The authors wish to acknowledge the assistance of Dr J. M. Naftalin with postmortem and pathological examinations, and the skilful technical assistance of Miss Mildred Wilson.

\section{REFERENCES}

Agnew, L. R. C. \& Cook, R. (1948-9). Brit. $\mathscr{F}$. Nutr. 2, 32 I.

Baker, F. (1948). Private communication.

Baker, F., Nasr, H. \& Morrice, F. (1949). F. gen. Microbiol. 3, I5.

Fridericia, L. S. (1926). Proc, int. Physiol. Congr. xII, Stockholm, p. 15.

Harris, L. J., Clay, J., Hargreaves, F. J. \& Ward, A. (1933). Proc. roy. Soc. B, rr3, 161.

Kon, S. K. (193 I). F. Hyg., Camb., 31, 543.

Richards, M. B. (1948). Private communication. 